\title{
Physical Environment Comfort Impacts on Office Employee's Performance
}

\author{
Shirley Jin Lin $\underline{\text { Chua }}^{1}$, Azlan Shah $\underline{A l i}^{1}$ and Melissa Ee Ling $\underline{\operatorname{Lim}}^{1}$ \\ ${ }^{1}$ Faculty of Built Environment, University of Malaya, Kuala Lumpur, Malaysia
}

\begin{abstract}
Office workplaces today is now no longer only consisting of passive and fixed activity but also towards a more flexible environment activity. The number of office workplaces is hiking from day to day which leads to the increase of the office workers. The productivity will be improved by providing optimum physical environment. The physical environment comfort in a workplace is claimed to be vital as it will encourages healthier, more productive and lower absenteeism rate among employees. The physical environment comfort encompassed optimum room temperature, relative humidity and illuminance level. This research intend to investigate the importance of physical environment comfort by evaluating the comfort based on the existing workplace and determine its effect on employee's performance. Evaluation between the selected case studies are made in the aspects of employee's comfort perceive health and absenteeism rate by wielding the elements of physical comfort consisting room temperature, relative humidity and illuminance level. Field study was carried out for 3 institutional building particularly management department. High correlations are found between room temperature, lighting and relative humidity with health related issue such as stuffy, easily tired and difficulty in concentration which affect employees' productivity and work performances.
\end{abstract}

\section{Introduction}

Most of the workers spend at least 8 hours daily in their life at their workplace. A well designed, furnished with optimum environment comfort office workplace is said that it will bring an achievement at the objectives of the organization and corporate goals to both the employees and clients. The issue arise when the factors of environment comfort influence their cognitive abilities and reducing their work performance. There is possible relationship that exists between the surrounding's office environment quality and the productivity of the employees [1]. The optimal indoor air temperature in office building is considered acceptable if $80 \%$ of the occupants are comfortable [2]. Wyon [3] states that thermal comfort is imperative, if the thermal condition is within the thermal comfort zone, employee's performance can be reduced by $5 \%$ to $15 \%$. As in stated by DOSH [4], most of the employees work comfortably in office at the temperature of between $23^{\circ} \mathrm{C}$ to $26^{\circ} \mathrm{C}$. Humidity level is also taken concerned in order to produce a better environment comfort in an office building. In a situation of lower humidity level, employees will be more uncomfortable from the resultant of dryness in skin as well as the difficulty in breathing from mouth or nose [5]. As for lighting level, it is a key factor for all the employees to get their job done. Without proper lighting, employees are impossible to finish their tasks comfortably. It is proven that when employees have their ability to control the lighting quality, they create a positive effect in their performance [6]. Therefore, in this research, a further relationship and how environment comfort in an office building will be affecting employee's productivity is carried out.

\section{Physical Comfort and Productivity}

Performance itself can be divided into two types mainly; task performance and contextual performance. There are two types of task performance where the first one is the actions that contribute to transforming raw materials to either goods or services. This could include contractor work, teaching, logistic and marketing. The second task performance is the technical core in an organization is maintained in a good position by coordinating and supervising that enable it to work perfectly. Meanwhile, contextual performance is the behaviour which enhance to the overall effectiveness through the social and psychological aspects in a workplace. It promotes the 
growth of the organization's network and does not contribute through the organization's core technical process. Contextual performance could be the surrounding environment in the office workplace, integration and cooperation with teammates and volunteering to perform any task which is not mainly part of the job [7]. The potential of unsuitable environment comfort in an office building will lead to various possible health issues. Raw, Garston [8] and Ronald, Catherine [9] highlighted that when employees are found to suffer from various symptoms such as eye irritation and running nose, dizziness, ease in feeling fatigue, dry skin and difficulty in concentrating over a period of time, it is indirectly reported in reduction of productivity.

Employees working performances are affected by their behaviour and responses. It is considered as an imperative intermediate factors that affect their work performances by indoor environment. According to Srivastava [10], this issue of discussion on the effect of an organization environment and structure towards the behaviour of all the employees working under it has been discussed and analysed since long ago. It is recorded that there are a huge number of middle-aged man office workers whom commit suicide in Japan [11]. It can be understand that it happened from the consequences of high stress and fatigue level among the employees. When employees are feeling uncomfortable with their physical environment in working area, they tend to feel tired and stress easily. This will lead to any unethical act whereby it will affect the performance and productivity of their work. Thus, human response towards their surrounding comfort will lead to their production level at the end of the day.

\section{Methodology}

The research is done by using qualitative method. Field study is done for 3 office building. The 3 selected case studies have several similar criteria where all of the offices used as office space with approximately 200 square meters to 300 square meters occupied by government employees their scope of work include writing and reading, computer task and occasional walking to deliver document between workstation. The sampling location for hygrometer is selected according to the matrix grid of 100 square meters meanwhile location for lux meter is placed at every alternate working desks.

\section{Finding and Discussion}

\subsection{Office Building A}

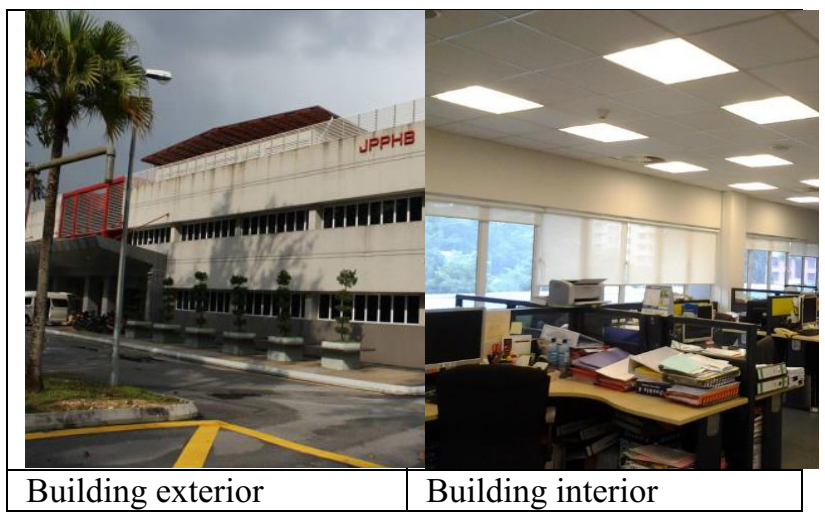

Figure 1: Exterior and interior of the building

In office building $A, 5$ points are selected to take the measurement of the existing surrounding temperature in the office building for every consecutive hour from 9.00 am until $4.00 \mathrm{pm}$. The room temperature in office building $\mathrm{A}$ is fluctuating throughout the day. This is due to the ability of the employees to control the room temperature through manual control air conditioning unit. All of the temperature obtained are in comfort zone as stated by DOSH [4] where the optimum temperature on an office building must be in $23^{\circ} \mathrm{C}$ to $26^{\circ} \mathrm{C}$ which is also supported by Shaharon and Jalaludin [12].

For relative humidity, the same points as measuring the room temperature. Most of the point shows reading of $45 \%$ to $55 \%$ which is in between of $40 \%$ and $70 \%$. It is still considered to be in acceptable range by referring to DOSH [4].

The points to take lighting level differ from the points in taking the measurement of surrounding temperature and relative humidity. By referring to MS1525 [13, 14], it states that lux reading of about 200 is needed for office work with infrequent reading and writing. In office building A, most of the points shows lighting level of in between 280 lux to 150 lux. It is considered to be optimum for daily working purpose.

\subsection{Office Building B}

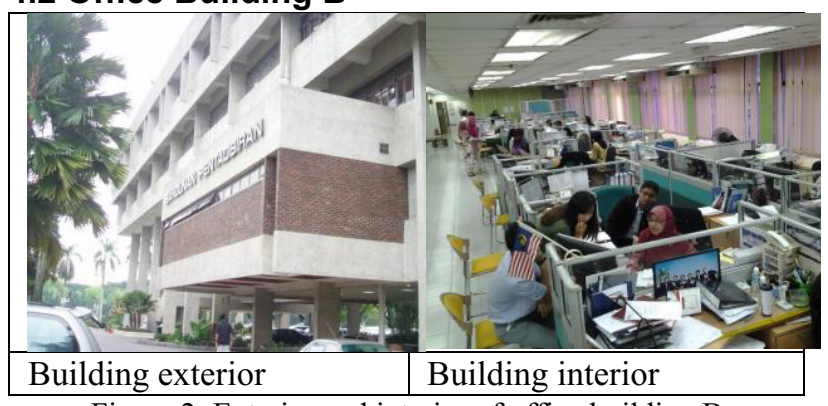

Figure 2: Exterior and interior of office building B

In office building B, three points are selected to measure the surrounding temperature of the office building. From the measurement obtained, office building B is considered to have optimum surrounding temperature by benchmarking with DOSH[4]. All the three points shows a consistent flow by having approximately of $24^{\circ} \mathrm{C}$ in the morning and drops to about $23^{\circ} \mathrm{C}$ in the afternoon then rises back to $24^{\circ} \mathrm{C}$ in the evening. This is a resultant from 
centralised air conditioning system where the employees are unable to change the temperature as accordance to their preference. Therefore, the room temperature measured are in very consistently changing accordance to the time of the day.

Relative humidity at office building B also shows a very consistent reading of approximately $52 \%$ to $56 \%$. As referring to the optimum requirement by DOSH [4], it is still considered as acceptable if the relative humidity is below $70 \%$.

The lighting level in office building B is obtained from eight different points which is located at different working desks. Office building B has high illuminance level that shows lux reading of nearly to 300 lux. This has exceeded the regular minimum requirement of having 200 lux for infrequent reading and writing task as has been stated by MS1525 [15]. However, by looking at another requirement from MS1525 [15] also, lighting level for office work where frequent reading and writing tasks are done there is approximately of 300 lux to 400 lux. Therefore, office building B is still considered to have acceptable lighting level by considering the tedious daily admin and office tasks done at there.

\subsection{Office Building C}

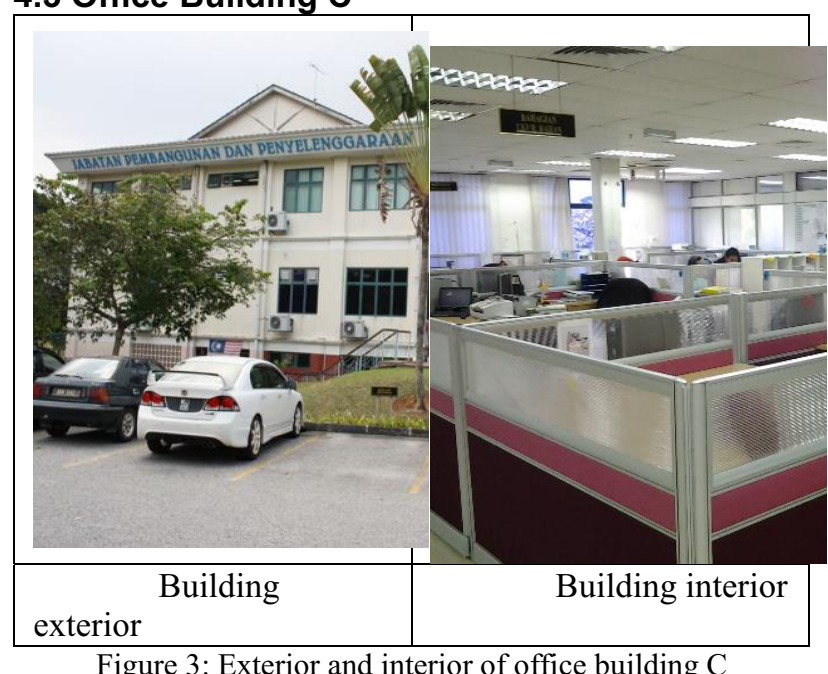

In office building $\mathrm{C}$, the surrounding room temperature obtained are quite balance throughout the office building The office building started off with very high room temperature of approximately $26^{\circ} \mathrm{C}$ and then dropped gradually until $12.00 \mathrm{pm}$. The room temperature hiked up again at $3.00 \mathrm{pm}$ due to the switching off of air conditioning during break period from $12.15 \mathrm{pm}$ to 2.45 pm.

The relative humidity in office building $\mathrm{C}$ is extremely high throughout the day. The relative humidity measured is averaged at $74 \%$. The recorded value has exceeded the requirement.

Six points are selected to measure the lighting level at office building $\mathrm{C}$. Office building $\mathrm{C}$ has large ${ }^{\text {a }}$ Corresponding author: shirleychua88@um.edu.my differentiation of lighting level throughout the office workplace. The lighting level that are above the benchmark of 200 lux suits the requirement for frequent reading and writing task in office building as stated by MS 1525 (2007)[14].

\subsection{Impact of Physical Environment Comfort on Productivity}

From the findings of the overall environment comfort, it has caused a different impact towards both employee's health and indirectly affecting absenteeism rate among the occupants of building. Several correlated health symptoms such as stuffy, tired or dry eye, easily tired, dry skin and difficulty in concentration are found in office building C. It is reasonable understand that under high humidity, it will bring an effect of feeling stuffiness and easily fatigue most of the time.

While occupants in office building A faced lighting and visual comfort such as easiness in tired, blur vision, glaring and tired eye seem to be more noticeable. Out of the 3 office building, occupants in office building B are comfortable with its surrounding room temperature, lighting and visual comfort.

\section{Conclusion}

The research proven that there is relationship room temperature, lighting and relative humidity with health related issue such as stuffy, easily tired and difficulty in concentration which affect employees' productivity and work performances. Thus, the surrounding physical environment comfort has impact on the health of the building occupants and indirectly affecting their productivity of work. 


\section{References}

1. Leaman, A., Dissatisfaction and office productivity. Facilities, 1995. 13(2): p. 13-19.

2. Dwyer, T., Comfort for Productivity in Offices. Building Services Journal, 2006. 6: p. 89 - 91.

3. Wyon, D.P., Indoor Environmental Effects on Productivity. Proceedings of ASHRAE Conference on Paths to Better Building Environments - IAQ 1996, 1996: p. 5-15.

4. DOSH, Industry Code of Practice on Indoor Air Quality 2010, M. Department of Occupational Safety and Health Ministry of Human Resources, Editor. 2010.

5. Sehgal, S., Relationship between Work Environment and Productivity. International Journal of Engineering Research and Applications (IJERA), 2012. 2(4): p. 1992 1995.

6. Veitch, J.A., Creating High-Quality Workplaces Using Lighting. Creating the Productive Workplace, 2005: p. 206 - 222.

7. Motowildo, S.J., W.C. Borman, and M.J. Schmit, A Theory of Individual Differences in Task and Contextual Performance. Human Performance, 1997. 10(2): p. 71-83.

8. Raw, G., W. Garston, and A. Leaman. Further Findings from the Office Environment Survey : Productivity. in 5th International Conference on Indoor Air Quality and Climate. 1990.

9. Ronald, C.K., et al., The World Health Organization Health and Work Performance
Questionnaire (HPQ). American College of Occupational and Environmental Medicine, 2003. 45: p. 156 - 174.

10. Srivastava, A.K., Effect of Perceived Work Environment on Employees' Job Behaviour and Organizational Effectiveness. Journal of the Indian Academy of Applied Psychology, 2008. 34(1): p. 47-55.

11. Tanabe, S., M. Haned, and N. Nishipana, Indoor Environment Quality and Productivity. Rehva Journal, 2007: p. 26-31.

12. Shaharon, M.N. and J. Jalaludin, Thermal Comfort Assessment : A Study Towards Worker's Satisfaction in a Low Energy Office Building. American Journal of Applied Sciences, 2012. 9(7): p. 1037 - 1045.

13. MS1525:2007, Code of Practice on Energy Efficiency and Use of Renewable Energy for Non-Residential Buildings (First Revision), S. Malaysia, Editor. 2007: Selangor, Malaysia.

14. Department of Standard Malaysia, Code of Practice on Energy Efficiency and Use of Renewable Energy for Non-Residential Buildings (First Revision). 2007, Department of Standard Malaysia: Selangor, Malaysia.

15. Department of Occupational Safety And Health (DOSH) , D., Industry Code of Practice on Indoor Air Quality 2010. 2010, DEPARTMENT OF OCCUPATIONAL SAFETY AND HEALTH MINISTRY OF HUMAN RESOURCES, MALAYSIA: Malaysia. 